\title{
High value of rapid diagnostic tests to diagnose malaria within children: A systematic review and meta-analysis
}

\author{
Wenjun Zhu' ${ }^{1}$ XiaoXiao Ling², \\ Wenru Shang ${ }^{1}$, Yanqiu Du ${ }^{1}$, \\ Jinyu Liu', Yuanyuan $\mathrm{CaO}^{3}$, \\ Mengmeng Yang ${ }^{3}$, Guoding \\ $\mathrm{Zhu}^{3,4,5}$, Jun $\mathrm{CaO}^{3,4,5}$, Jiayan \\ Huang ${ }^{1}$ \\ ${ }^{1}$ Key Lab of Health Technology \\ Assessment, National Health \\ Commission; School of Public Health, \\ Fudan University, Shanghai, China \\ ${ }^{2}$ Department of Statistical Science, \\ University College London, London, UK \\ ${ }^{3}$ National Health Commission Key \\ Laboratory of Parasitic Disease Control \\ and Prevention, Jiangsu Provincial \\ Key Laboratory on Parasite and Vector \\ Control Technology, Jiangsu Institute \\ of Parasitic Diseases, Wuxi, Jiangsu, \\ China \\ ${ }^{4}$ Center for Global Health, School \\ of Public Health, Nanjing Medical \\ University, Nanjing, Jiangsu, China \\ ${ }^{5}$ Public Health Research Center, \\ Jiangnan University, Wuxi, Jiangsu, \\ China
}

\section{Correspondence to:}

Jiayan Huang, PhD

Fudan University

P. O. Box 197

YiXueYuan Road 138

Shanghai 200032

People's Republic of China

jiayanhuang@fudan.edu.cn

Jun Cao, PhD

Jiangsu Institute of Parasitic Diseases

Meiyuan 117

Wuxi 214064

Jiangsu

People's Republic of China

caojuncn@hotmail.com
Background Children aged under five years accounted for $61 \%$ of all malaria deaths worldwide in 2017, and quicker differential diagnosis of malaria fever is vital for them. Rapid diagnostic tests (RDTs) are strips to detect Plasmodium-specific antigens promptly and are helpful in resource-limited areas. Thus, our aim is to assess the diagnostic accuracy of RDTs for malaria in children against the gold standard.

Methods MEDLINE, Web of Science, EMBASE, Cochrane Library, the China National Knowledge Infrastructure, Wanfang, and Sinomed databases were systematically searched on August 23, 2019. Studies that compared RDTs with microscopy or polymerase chain reaction in malaria diagnoses for children were eligible. Relevant data were extracted. The quality of studies was evaluated using the revised Quality Assessment of Diagnostic Accuracy Studies instrument. Meta-analyses were carried out to calculate the pooled estimates and 95\% confidence intervals of sensitivity and specificity.

Results 51 articles were included. For diagnostic accuracy, the pooled estimates of the sensitivity and specificity of RDTs were 0.93 (95\% confidence interval $(\mathrm{CI})=0.90,0.95)$ and $0.93(95 \% \mathrm{CI}=0.90,0.96)$ respectively. Studies were highly heterogeneous, and subgroup analyses showed that the application of RDTs in high malaria transmission areas had higher sensitivity but lower specificity than those in low-to-moderate areas.

Conclusions RDTs have high accuracy for malaria diagnosis in children, and this characteristic is more prominent in high transmission areas. As they also have the advantages of rapid-detection, are easy-to-use, and can be cost-effective, it is recommended that the wider usage of RDTs should be promoted, especially in resource-limited areas. Further research is required to assess their performance in WHO South-East Asia and Americas Region.

Malaria is a preventable, curable but life-threatening disease caused by parasites including Plasmodium falciparum (Pf), Plasmodium vivax (Pv), Plasmodium knowlesi (Pk), Plasmodium malariae (Pm), and Plasmodium ovale (Po), of which $P$. falciparum and $P$. vivax are the most prevailing and $P$. falciparum the most deadly [1,2]. In 2017, there were around 219 million cases of malaria worldwide, and the attributable mortality was nearly 435 thousand [3]. Especially, children aged under 5-year-old accounted for $61 \%$ of all malaria deaths around the world, thus they are the most susceptible group affected by malaria $[3,4]$. Contrast to adults, children are more vulnerable to infectious diseases, and quicker differential diagnosis between malaria and non-malaria fever is needed for lessening death and severe cases. 
According to World Health Organization (WHO), all suspected malaria cases should take a parasitological test to confirm the diagnosis using either microscopy or malaria rapid diagnostic tests (RDTs) [5]. The aim of this strategy is to reduce the unnecessary use of Artemisinin-based combination therapies (ACT) and prevent potential drug resistance [6]. In addition, it can improve the diagnosis of other non-malaria febrile diseases. Microscopic examination of blood slides is considered as the "gold standard" for malaria diagnosis, but it is time-consuming and requires well-trained personnel and adequate laboratory equipment, which is hard to maintain in most of the endemic areas $[7,8]$. RDTs can detect specific antigens produced by Plasmodium in individual blood, including histidine-rich protein-2 (HRP2), lactate dehydrogenase (LDH), and aldolase. HRP2 is specific for P. falciparum, while aldolase can be found in all species (pan-specific). LDH can be divided into three categories: Pf-specific, Pv-specific and pan-specific. Antibodies against these antigens can be combined in one type of RDTs to detect different Plasmodium species $[9,10]$. According to Bell and his colleagues, RDTs can be divided into 7 types depending on their target antigens (Appendix S1 in the Online Supplementary Document) [11]. Besides, pan-specific LDH only and Pv-specific LDH only tests are also available now [12]. The typical operation of RDTs is to combine a drop of finger-pricked blood and a couple of drops of buffer into RDTs cassette and wait for several minutes until the results appear on the strip. Compared to microscopy, the tests are simple to perform and interpret while providing rapid results. So, it can be used at the community level. Polymerase chain reaction (PCR) is one of nucleic acid amplification techniques, which is more sensitive than microscopy, and it can also be regarded as the "gold standard". However, it has a higher requirement on trained technicians and standard laboratory. Thus, it does not fit the field malaria diagnosis currently and is mainly operated in epidemiological research $[9,13]$.

Although WHO has established the diagnostic criteria, the use of parasitological tests to diagnose malaria for children was still depressed. WHO African Region accounted for $92 \%$ of all malaria cases in 2017 , but according to 58 household surveys conducted in 30 sub-Saharan African countries, in 2015-2017, the median percentage of febrile children who received a diagnostic test in public health facilities was only 59\% [3], which meant that there were still around two-fifths children who did not have the access to the parasitological diagnosis. Since the majority of African health facilities lack the capacity and/or device to perform microscopy [14], RDTs, which are easy to use, will be helpful to provide rapid diagnosis and avert avoidable death for children, to reach SDG 3.2 - end preventable deaths of newborns and children under-5 by 2030, and the target set by the Global Technical Strategy for Malaria 2016-2030, ie, at least $90 \%$ malaria incidence and mortality should be reduced by 2030 .

The validity of RDTs has been approved in recently published systematic reviews $[9,12,15]$, but all of them do not have restrictions on the age of the target population. The validity of RDTs in childhood malaria diagnosis has its own characteristics and may be different from adults. That is because the immunity towards Plasmodium increases with age [16], and the anti-parasite ability of children is lower than adults. It would lead to a higher parasite density of childhood malaria infection if other conditions are the same [17].

Clinical evidence has been accumulated on the operations of RDTs for childhood malaria diagnosis. However, wide disparities in their performance have been observed across studies [18-22]. These discrepancies may be attributed to different study designs, sample size, study location and reference standard used. Therefore, a systematic review was conducted to provide a comprehensive evaluation of the diagnostic accuracy and investigate the performance of RDTs against the gold standard in malaria diagnosis among children.

\section{METHODS}

\section{Search strategy and selection criteria}

A systematic approach was used to search the following databases: Pubmed, Web of Science, EMBASE, Cochrane Library, the China National Knowledge Infrastructure (CNKI), Wanfang Data, and Sinomed. The latter three are Chinese databases. The search strategies were outlined in Appendix S2 in the Online Supplementary Document and no restriction was imposed. The search was undertaken on August 23, 2019, and the references of all eligible studies were checked manually to identify extra relevant articles.

The inclusion criteria were as follows: (1) Primary studies that evaluated the diagnostic accuracy of RDTs. (2) The microscopic examination of blood smears or PCR was selected as the gold standard. (3) Participants were children. (4) Studies that reported the direct comparison results between RDTs and the gold 
standard. The exclusion criteria were as follows: (1) Studies that were case reports, reviews, editorials, letters, comments, and conference abstracts. (2) Studies that did not present enough information to extract or calculate the number of true-positives, false-positives, true-negatives, and false-negatives. The title and abstract of all relevant articles were read by three reviewers independently according to the inclusion and exclusion criteria during the first round of screening. Then the full texts of the eligible studies were rechecked based on the same criteria. Any disagreement between three reviewers was resolved by discussion.

\section{Data extraction and quality assessment}

The following data were independently extracted by three reviewers from eligible studies using Microsoft Excel 2016 (Microsoft Inc, Seattle WA, USA): (1) study characteristics: journal, publication year, first author and his/her institution, study period, study setting, and study design. (2) participants' characteristics: the inclusion and exclusion criteria, sample size, the number of malaria cases, the age range and sex distribution of participants, and the parasite density of Plasmodium. (3) RDTs characteristics: commercial brand, and specific Plasmodium species and antigens detected. (4) RDTs performance: the reference standard, and the number of true-positives, false-positives, true-negatives, and false-negatives. Any discrepancy between three reviewers was resolved by discussion. If only a subset of participants met the selection criteria, data were extracted only for the subgroup.

The revised Quality Assessment of Diagnostic Accuracy Studies (QUADAS-2) tool was used to assess the methodological quality of the eligible studies [23], as recommended by the Cochrane Collaboration. The tool has four domains: patient selection, index test, reference standard, and flow and timing. Each domain was scored as "high/low risk of bias" and "high/low applicability concern", except for the last one which only contains the risk of bias section. If insufficient data were reported, the corresponding section would be classified as "unclear". Reviewers assessed the quality of studies independently using Review Manager 5.3 and discussed the inconsistencies. The criteria for each section are listed in Appendix S3 in the Online Supplementary Document.

\section{Statistical analysis}

We estimated the sensitivity and specificity of each study with $95 \%$ confidence intervals (CI) and presented the results in forest plots. Then we used the Midas module in Stata 12.1 (StataCorp LLC, Texas, USA) to calculate the pooled estimates of the sensitivity, specificity, positive likelihood ratio, negative likelihood ratio, and diagnostic odds ratio. Midas is a comprehensive program for undertaking meta-analysis of diagnostic test accuracy in Stata. Its primary data synthesis is based on the bivariate mixed-effects regression framework. A hierarchical summary receiver operating characteristic curve (HSROC) was fitted and funnel plots were presented respectively to show the comprehensive diagnostic value of RDTs and the potential publication bias among eligible studies. Compared with the summary receiver operating characteristic (SROC) model, the HSROC model allows more between and within-study variability [24]. It was adopted as studies included are expected to show considerable heterogeneity in diagnostic accuracy [25]. We also performed the Q test to assess the heterogeneity among the included studies. The extent of heterogeneity was quantified by $\mathrm{I}^{2}$ measure [26]. If the heterogeneity was significant $\left(I^{2}>50 \%\right)$, we used Meta-disc 1.4.0 software (the Unit of Clinical Biostatistics team of the Ramón y Cajal Hospital, Madrid, Spain) to explore whether a threshold effect existed. Furthermore, meta-regression was conducted to investigate the potential sources of heterogeneity. Covariates included local malaria transmission type, study design, sampling method, reference standard, sample size, geographic location, blinding status, RDTs type, and target antigens. In the regression, the accuracy measure was relative diagnostic odds ratio (RDOR). The coefficients of covariates indicated the change in the diagnostic performance of the RDTs under each study per unit increase in the covariates. In other words, $P<0.05$ represented that the corresponding covariates were the major sources of heterogeneity. Subgroup analyses based on the sources of heterogeneity were subsequently conducted by Stata (Stata Corp, College Station, TX, USA).

For meta-regression and subgroup analyses, transmission type was divided into four categories: high, low-to-moderate, mixed and unclear. The transmission type was classified as "high" if the authors described it as "hyperendemic", "perennial", "holoendemic" or "high"; "low-to-moderate" when it was "mesoendemic", "sporadic", "moderate" or "low"; "mixed" if it was described as "seasonal" or when multiple sites of different transmission types were included; "unclear" if the transmission type was not mentioned. 


\section{RESULTS}

\section{Results of the search}

A total of 9731 relevant articles were identified. After removing duplicates, 5933 articles were selected. 5861 articles were excluded based on the criteria. The full texts of 72 articles were evaluated and 51 of them were eventually included. Among them, the most common reason for exclusion was the lack of data for a $2 \times 2$ table. The detailed process for selection is shown in Figure 1.

Out of 51 studies included in the review, two evaluated the validity of RDTs when they were used to monitor the effects of ACT treatment, and the others assessed the diagnostic capacity of RDTs. Since HRP2 will be cleared slowly from bloodstream if the treatment of $P$. falciparum is successful and it can contribute to a higher false-positive rate of RDTs [27], our analy-

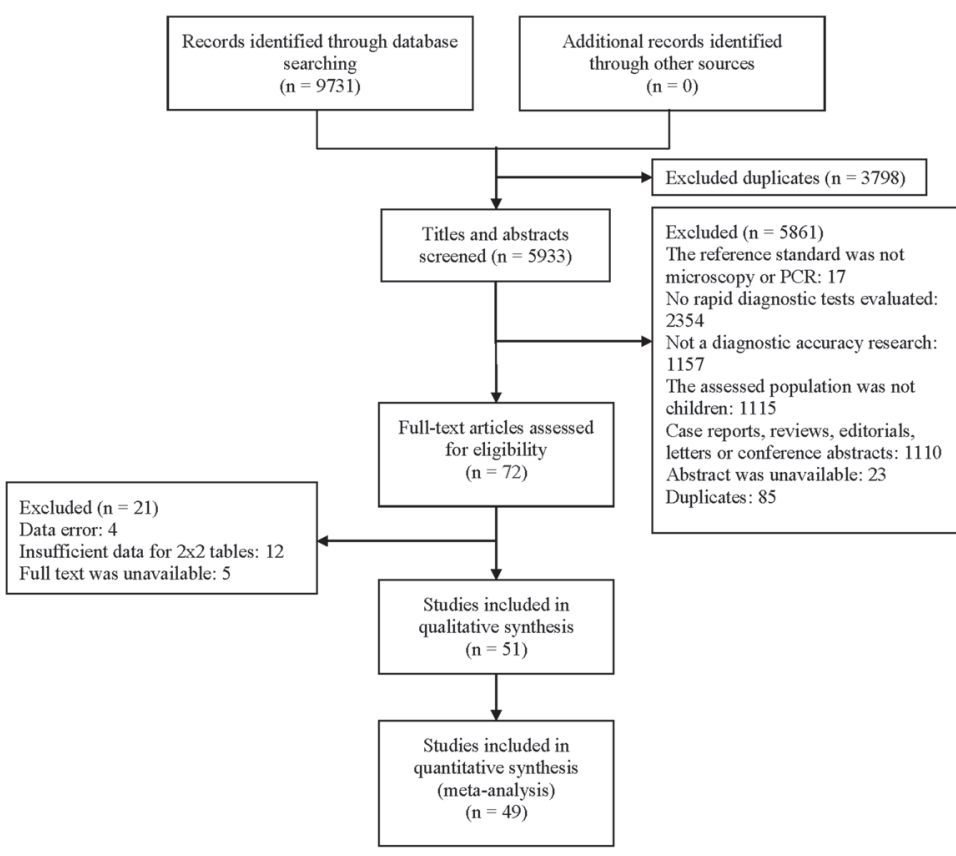

Figure 1. Flowchart of the selection procedure. PCR - polymerase chain reaction. ses were grouped into two parts according to the usage time of RDTs (before or after ACT treatment). There were 9 studies that adopted multiple types of RDTs and/or reference standards: 6 studies evaluated 2 types of RDTs [28-33], 2 studies evaluated 3 types of RDTs [18,34], and 2 studies selected two different types of reference standards [32,35]. Particularly, in one study, two staffs read the RDTs strips respectively, so there were two different results for each type of RDTs [29]. As enrolled children were asked to retest blood samples during the follow-up regularly, the studies that assessed the RDTs capacity for monitoring the effect of ACT treatment all have multiple test evaluations. As a result, we had 82 test evaluations reporting a total of 57312 test results. Among them, 34.45\% of tests (19746) showed the positive result against the reference standard. Most of the studies included were conducted in Africa $(n=47)$, and the rest of them happened in Asia (three in India and one in Pakistan). The detailed characteristics of the included studies were summarized in Table 1.

\section{The methodological quality of the included studies}

The overall methodological quality of studies included was relatively high, as the scores of risk of bias and applicability concerns in the four domains were mainly low. Most studies $(n=41)$ enrolled consecutive or random sample of patients. None of them were case-control studies. 17 studies adopted double-blind method, and 1 study was single-blind, but the rest did not supply sufficient information. 6 studies selected PCR as the reference standard, 43 studies took microscopy as the reference standard, and 2 studies chose both. $31.37 \%$ (16/51) of the eligible studies were scored to have a high risk of bias in the flow and timing domain since they did not include all patients in the analysis. $35.29 \%(18 / 51)$ of included studies had a high applicability concern in patient selection domain because of their unrepresentative samples. The results of the methodological quality were shown in Figure 2, Panel A and Panel B.

\section{Diagnostic accuracy of RDTs}

There were 63 test evaluations that focused on the diagnostic accuracy of RDTs $[6,18-22,28-32,34-59,61-$ 72]. 59 were conducted in Africa and 4 in Asia. 55 tests selected microscopy as the reference standard and 8 chose PCR. The median sample size was 400 (range: 102 - 6260). 14 tests evaluated the performance of RDTs in a high malaria transmission setting, 6 in low-to-moderate and 20 in mixed.

Sensitivities of tests ranged from 0.00 to 1.00 , and specificities from 0.08 to 1.00 (Figure 3 ). The pooled summary of sensitivity and specificity (95\% CI) of RDTs were $0.93(0.90-0.95)$ and $0.93(0.90-0.96)$ respectively. The pooled estimates for the positive likelihood ratio, negative likelihood ratio, and diagnostic odds ratio (95\% CI) were 13.67 (8.94-20.90), 0.07 (0.05-0.10), and 192.67 (111.46-333.06) respec- 


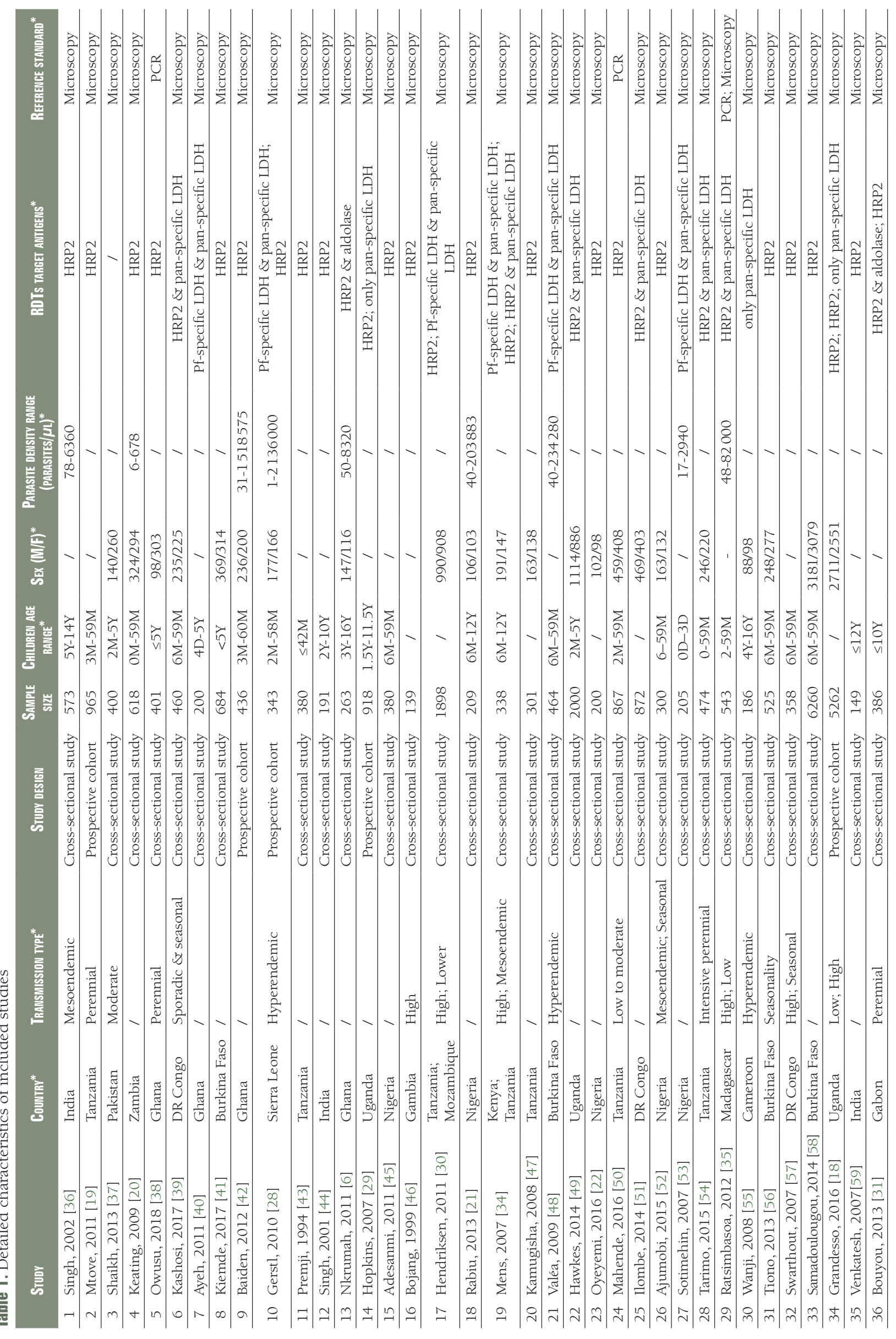



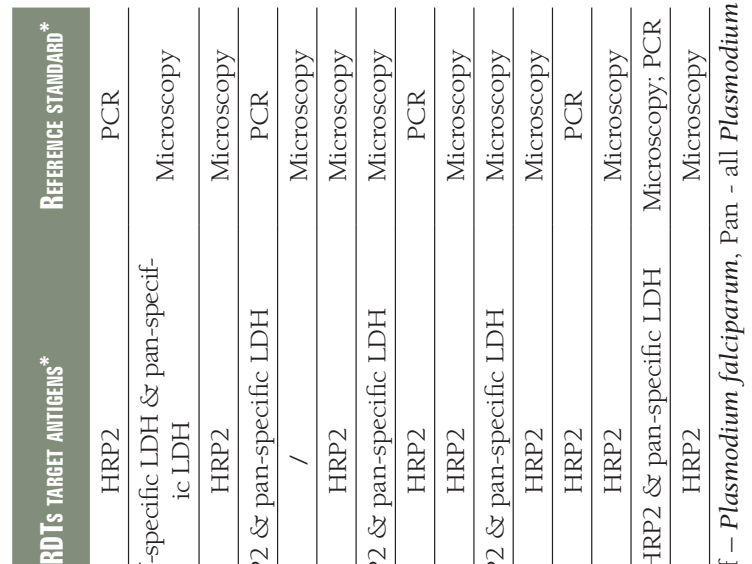

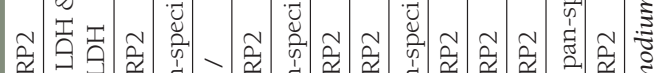

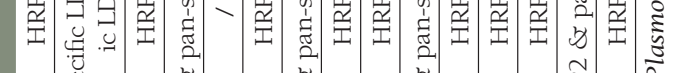

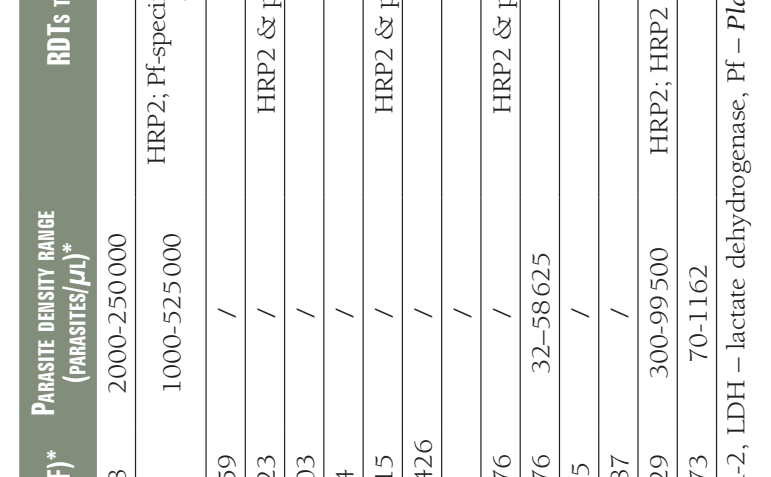

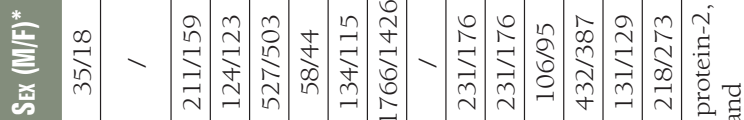

종

(1)

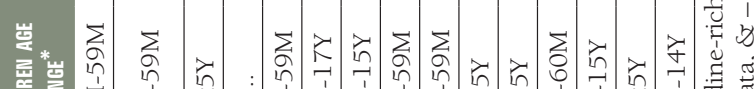

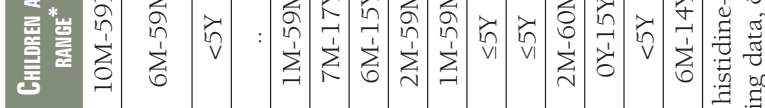

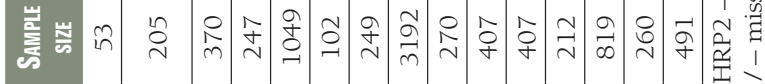

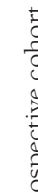

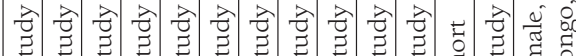

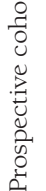

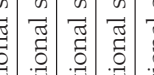

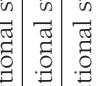

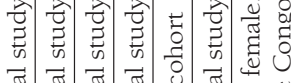

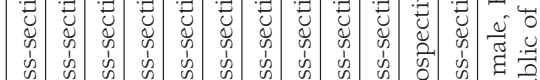

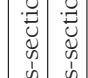

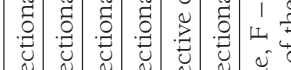
a.

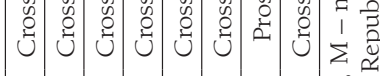

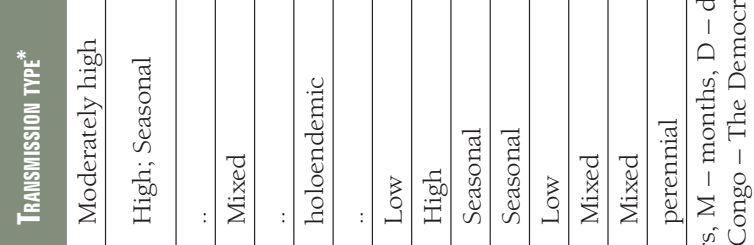

* 言 章

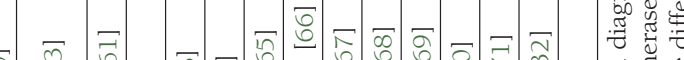

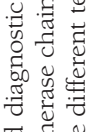

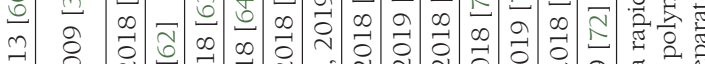

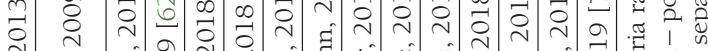
든

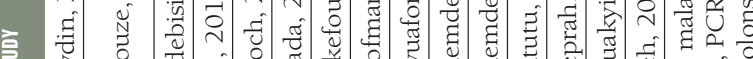

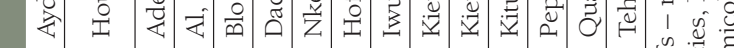

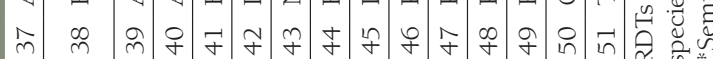

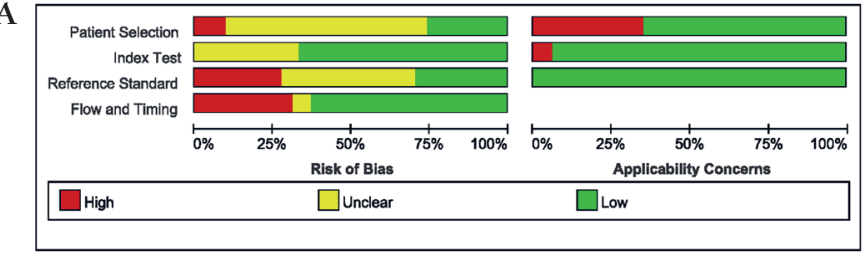

\section{B}

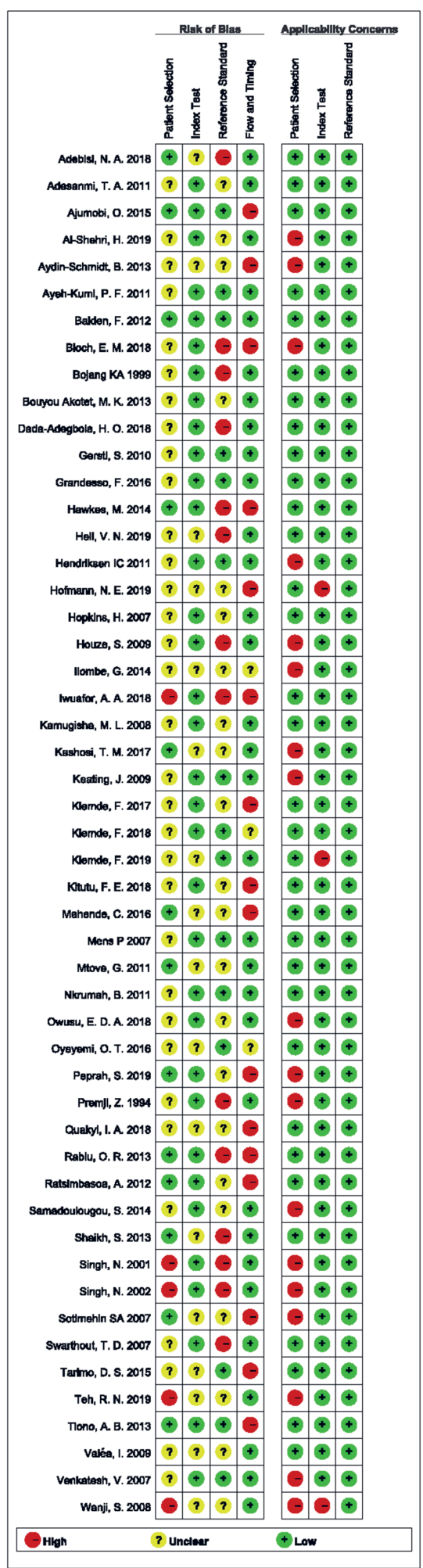

Figure 2. Methodological quality assessment of studies included in the review. Panel A. Overall quality of studies included in the review. Panel B. Detailed quality of studies included in the review. 


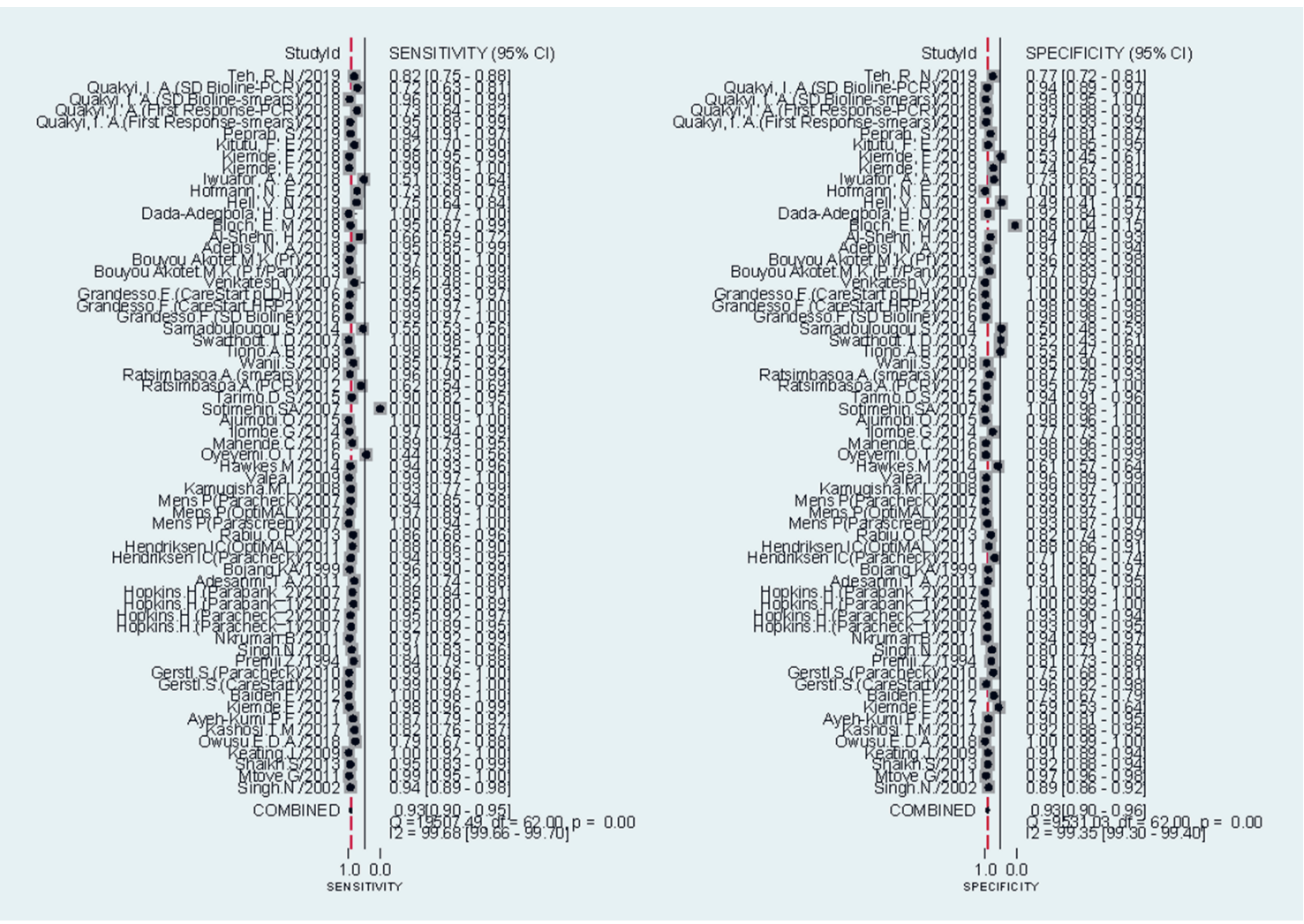

Figure 3. Forest plots of sensitivity and specificity of RDTs.

tively. HSROC curve summarized the sensitivity and specificity of RDTs in Figure 4. The area under the curve is close to $100 \%$, indicating that the performance of RDTs was satisfactory. High heterogeneity was observed between studies (Cochrane's $Q=2182.22, I^{2}=100.00, P<0.001$ ), thus we explored its source through the threshold effect analysis and meta-regression. The results suggested that there was no threshold effect between studies $(P=0.06)$, while transmission type, sampling method and study design were the major sources of heterogeneity $(P<0.05)$. The results of the meta-regression were shown in Table 2 . In addition, the effect of each variable on the accuracy of RDTs was presented by forest plots if the variable was categorical (Figure 5, Panel A and Panel B), and by scatter plots if it was continuous (Figure 6, Panel A and Panel B).

Subgroup analyses were conducted and the results were shown in Table 3. In brief, RDTs conducted in high malaria transmission areas had higher sensitivity but lower specificity compared to low-to-moderate areas. The studies with consecutive or random sample of patients presented higher sensitivity than others.

Table 2. Meta-regression analysis of diagnostic accuracy

\begin{tabular}{|c|c|c|c|c|c|}
\hline & Coefficient & Standard error & P-value & RDOR & $95 \%$ CI \\
\hline Cte & 7.83 & 2.23 & 0.00 & NA & NA \\
\hline $\mathrm{S}$ & -0.40 & 0.12 & 0.00 & NA & NA \\
\hline Transmission type & -0.46 & 0.16 & 0.00 & 0.63 & $0.46-0.86$ \\
\hline Study design & 1.18 & 0.58 & 0.05 & 3.24 & $1.01-10.45$ \\
\hline Sampling method & -2.16 & 0.83 & 0.01 & 0.12 & $0.02-0.61$ \\
\hline RDTs type & -0.23 & 0.25 & 0.38 & 0.80 & $0.48-1.32$ \\
\hline Reference standard & -1.32 & 0.74 & 0.08 & 0.27 & $0.06-1.19$ \\
\hline HRP2 based or not & 0.49 & 0.88 & 0.58 & 1.63 & $0.28-9.51$ \\
\hline Sample size & 0.00 & 0.00 & 0.05 & 1.00 & $1.00-1.00$ \\
\hline Continent & 1.57 & 1.11 & 0.16 & 4.82 & $0.52-44.32$ \\
\hline Blinding status & -0.33 & 0.28 & 0.25 & 0.72 & $0.41-1.27$ \\
\hline
\end{tabular}

RDTs - malaria rapid diagnostic tests, HRP2 - histidine-rich protein-2, NA - not applicable, CI - confidence interval, RDOR - relative diagnostic odds ratio, Cte - constant term in the equation, $\mathrm{S}-$ a measure of threshold 


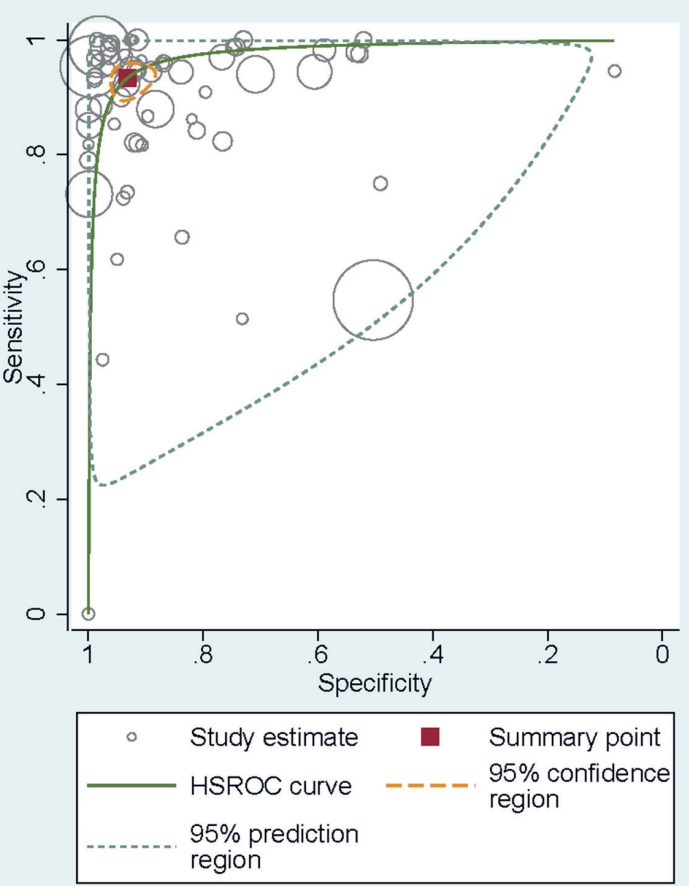

Figure 4. HSROC curve of sensitivity vs specificity of RDTs. HSROC - hierarchical summary receiver operating characteristic curve.
Both sensitivity and specificity estimated by prospective cohort studies appeared to be higher in comparison with cross-sectional studies. A funnel plot was presented in Figure 7. It demonstrated the existence of publication bias $(P=0.04)$, and it was found that studies with high accuracy results tended to be published.

Many studies discussed the diagnostic value of HRP2 based RDTs vs LDH based RDTs $[73,74]$, and the problem about which type of RDTs is better still exists. Although target antigens were not the major sources of heterogeneity, a subgroup analysis was performed based on it. Results showed that HRP2 based RDTs had higher sensitivity but lower specificity than RDTs that did not contain HRP2 (Table 3). But there was no statistically significant difference.

\section{RDTs capacity for monitoring the effect of ACT treatment}

19 tests evaluated RDTs' capacity of monitoring the effect of ACT treatment $[33,60]$. All were conducted in Africa. Fourteen tests took microscopy as the reference standard and five took PCR. Since the days after initial treatment is an important factor affecting the accuracy of RDTs, we analyzed the results based on this framework. Consequently, after categorizing based on the follow-up period, there was no more than 3 tests within each category, and thus we could not perform a meta-analysis (To perform Midas, a minimum of four $2 \times 2$ tables is required). In the lack of statistical pooling, we presented the findings in a narrative table (Table 4). In short, the specificity of HRP2 based RDTs increased with the follow-up period. And at early stages after the initial treatment, the specificity of Pf-LDH based RDTs was much higher than HRP2 based RDTs.

\section{DISCUSSION}

Our results demonstrated that RDTs had relatively high sensitivity and specificity for malaria diagnosis in children and all the findings were reported based on the PRISMA Checklist (Appendix S4 in the Online Supplementary Document) [75]. Since there is no previous systematic review focused on children,
A

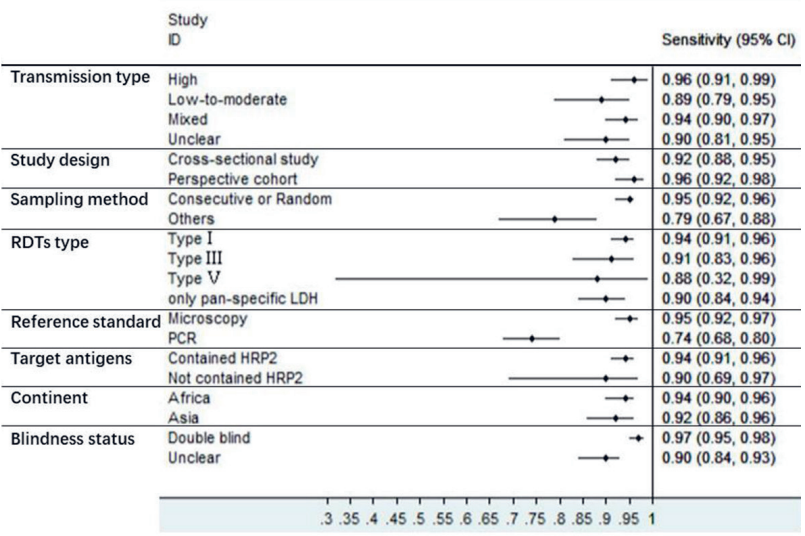

B

\begin{tabular}{|c|c|c|c|}
\hline & $\begin{array}{l}\text { Study } \\
\text { D }\end{array}$ & & Specificity ( $95 \% \mathrm{Cl}$ ) \\
\hline \multirow{4}{*}{ Transmission type } & High & $\longrightarrow$ & $0.92(0.85,0.96)$ \\
\hline & Low-to-moderate & $\longrightarrow$ & $0.96(0.89,0.99)$ \\
\hline & & $\longrightarrow$ & $0.94(0.88,0.97)$ \\
\hline & Unclear & $\longrightarrow$ & $0.92(0.81,0.97)$ \\
\hline \multirow{2}{*}{ Study design } & Cross-sectional study & $\rightarrow$ & $0.91(0.86,0.94)$ \\
\hline & Perspective cohort & $\rightarrow$ & $0.97(0.94,0.99)$ \\
\hline \multirow[t]{2}{*}{ Sampling method } & Consecutive or Random & $\rightarrow$ & $0.93(0.89,0.95)$ \\
\hline & Others & & $0.95(0.85,0.99)$ \\
\hline \multirow[t]{4}{*}{ RDTs type } & Type I & $\rightarrow$ & $0.92(0.88,0.95)$ \\
\hline & Type III & & $0.87(0.78,0.93)$ \\
\hline & Type V & $\longrightarrow$ & $0.97(0.90,0.99)$ \\
\hline & only pan-specific LDH & & $1.00(0.98,1.00)$ \\
\hline \multirow{2}{*}{ Reference standard } & Microscopy & $\rightarrow$ & $0.92(0.88,0.95)$ \\
\hline & PCR & $\longrightarrow$ & $0.98(0.92,0.99)$ \\
\hline \multirow[t]{2}{*}{ Target antigens } & Contained HRP2 & $\rightarrow$ & $0.91(0.87,0.94)$ \\
\hline & Not contained HRP2 & & $0.99(0.96,1.00)$ \\
\hline \multirow{2}{*}{ Continent } & Africa & $\rightarrow$ & $0.93(0.89,0.96)$ \\
\hline & Asia & & $0.95(0.75,0.99)$ \\
\hline \multirow[t]{2}{*}{ Blindness status } & Double blind & $\longrightarrow$ & $0.93(0.87,0.96)$ \\
\hline & Unclear & $\rightarrow$ & $0.94(0.90,0.97)$ \\
\hline
\end{tabular}

Figure 5. The effect of each categorical variables on the accuracy of RDTs. Panel A. The effect of each categorical variables on the sensitivity of RDTs. Type II, type unclear, and single-blind groups did not have enough test evaluations to perform meta-analysis. HRP2 - histidine-rich protein-2. LDH = lactate dehydrogenase. Pan = all Plasmodium species. PCR - polymerase chain reaction. Panel B. The effect of each categorical variables on the specificity of RDTs. Type II, type unclear, and single-blind groups did not have enough test evaluations to perform meta-analysis. HRP2 - histidine-rich protein-2. LDH - lactate dehydrogenase. Pan - all Plasmodium species. PCR - polymerase chain reaction. 


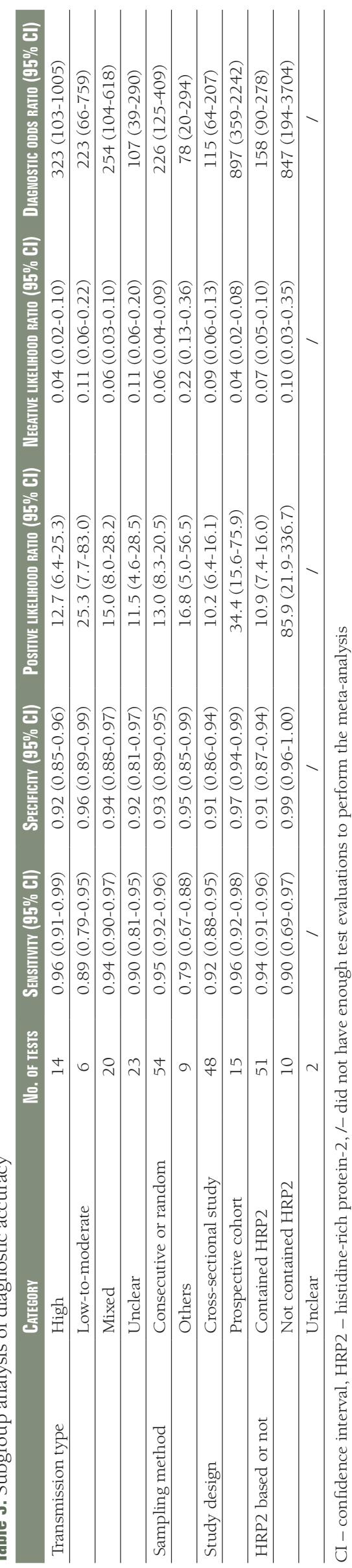

A

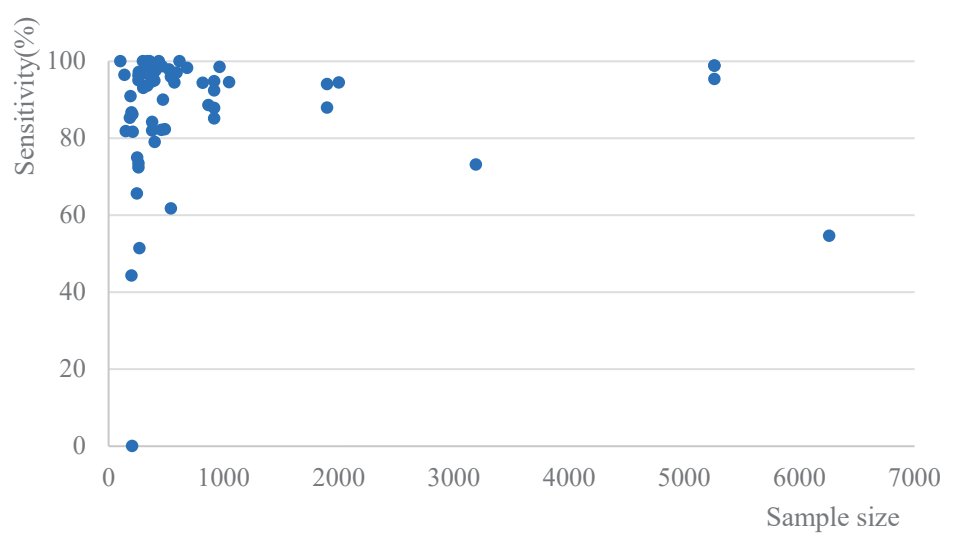

B

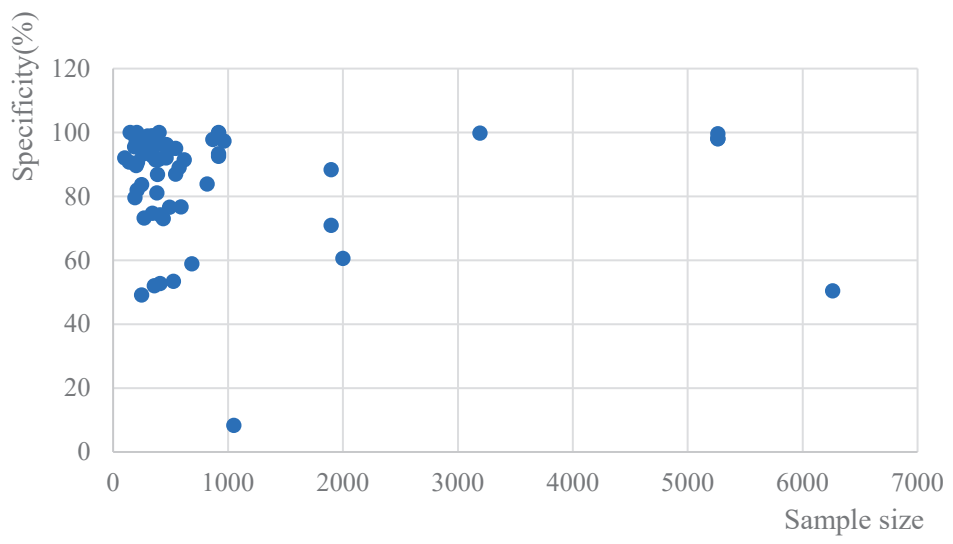

Figure 6. The effect of sample size on the accuracy of RDTs. Panel A. The effect of sample size on the sensitivity of RDTs. Panel B. The effect of sample size on the specificity of RDTs.

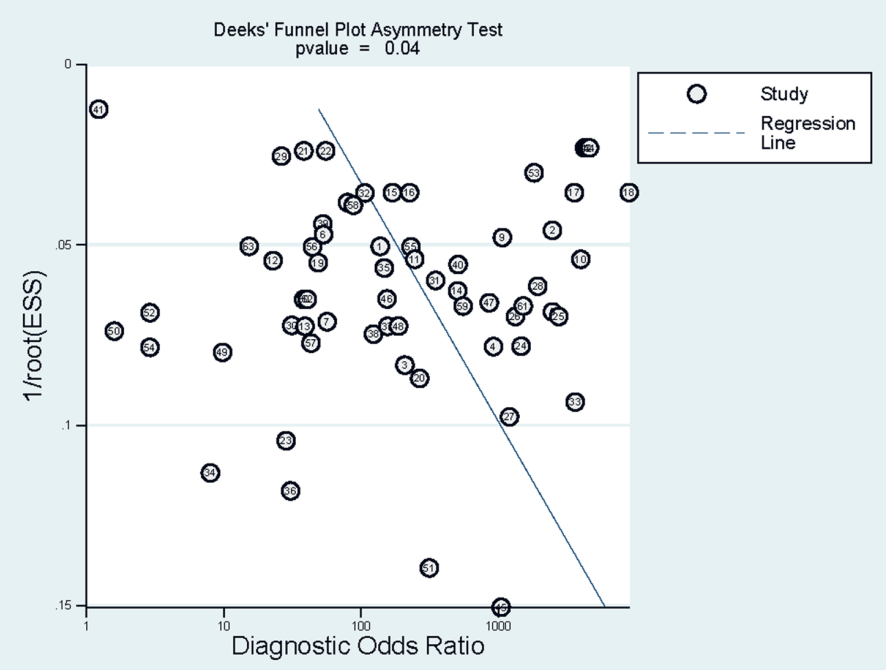

Figure 7. Publication bias of studies included in the review. 
Table 4. RDTs capacity for monitoring the effect of ACT treatment classified by days of follow-up

\begin{tabular}{|c|c|c|c|c|c|c|c|c|}
\hline & RDTS target AMtigenS & $\begin{array}{l}\text { DAYS AFTER INITIAL } \\
\text { TREATMENT }\end{array}$ & TP & TN & FP & FN & Sensitivity (\%) & SPECIFICITY (\%) \\
\hline \multirow[t]{5}{*}{ Aydin-Schmidt, 2013 [60] } & HRP2 & Day 14 & 3 & 8 & 32 & 0 & 100.00 & 20.00 \\
\hline & & Day 21 & 1 & 15 & 27 & 0 & 100.00 & 35.71 \\
\hline & & Day 28 & 1 & 24 & 18 & 0 & 100.00 & 57.14 \\
\hline & & Day 35 & 1 & 32 & 10 & 0 & 100.00 & 76.19 \\
\hline & & Day 42 & 2 & 38 & 3 & 0 & 100.00 & 92.68 \\
\hline \multirow[t]{7}{*}{ Houze, 2009 [33] } & HRP2 & Day 3 & 35 & 28 & 134 & 0 & 100.00 & 17.28 \\
\hline & & Day 7 & 6 & 49 & 115 & 1 & 85.71 & 29.88 \\
\hline & & Day 14 & 6 & 87 & 69 & 1 & 85.71 & 55.77 \\
\hline & & Day 21 & 14 & 104 & 38 & 2 & 87.50 & 73.24 \\
\hline & & Day 28 & 13 & 92 & 63 & 2 & 86.67 & 59.35 \\
\hline & & Day 35 & 9 & 79 & 4 & 2 & 81.82 & 95.18 \\
\hline & & Day 42 & 2 & 73 & 4 & 1 & 66.67 & 94.81 \\
\hline \multirow[t]{7}{*}{ Houze, 2009 [33] } & Pf-specific LDH \& pan-specific LDH & Day 3 & 28 & 141 & 21 & 7 & 80.00 & 87.04 \\
\hline & & Day 7 & 5 & 151 & 13 & 2 & 71.43 & 92.07 \\
\hline & & Day 14 & 5 & 150 & 6 & 2 & 71.43 & 96.15 \\
\hline & & Day 21 & 16 & 137 & 5 & 0 & 100.00 & 96.48 \\
\hline & & Day 28 & 13 & 122 & 3 & 2 & 86.67 & 97.60 \\
\hline & & Day 35 & 9 & 81 & 2 & 2 & 81.82 & 97.59 \\
\hline & & Day 42 & 2 & 77 & 0 & 1 & 66.67 & 100.00 \\
\hline
\end{tabular}

RDTs - malaria rapid diagnostic tests, HRP2 - histidine-rich protein-2, LDH - lactate dehydrogenase, Pf - Plasmodium falciparum, Pan - all Plasmodium species, TP - true-positives, TN - true-negatives, FP - false-positives, FN - false-negatives

the results were compared with those of the whole population. Abba's research found that the sensitivity of RDT varied between 0.915 and 0.995 , while its specificity ranged from 0.906 and 0.987 [9], which is comparable to our results. Moreover, in high transmission areas, the sensitivity and specificity were higher among children (0.96 and 0.92 , respectively) than the whole population (0.937 and 0.896 , respectively) [9]. This may relate to the fact that because adults have greater immune status than children, adult patients with malaria is more likely to have lower parasite density $[60,76]$, and it could be difficult for RDTs to detect the low concentration of antigens among them. This characteristic makes RDTs more suitable for childhood malaria detection in high transmission areas. Another research conducted by Li calculated the accuracy of HRP2 based RDTs [15]. Comparatively, it had lower sensitivity (0.94 vs 0.96, respectively) but higher specificity ( 0.91 vs 0.86 , respectively) in children than in adults.

Besides high diagnostic accuracy, RDTs also have the advantages of rapid detection and are easy-to-use, making it feasible to utilize it at primary health care centers. These advantages can be particularly important for P. falciparum detection, as it can progress rapidly from an uncomplicated febrile illness to potentially deadly disease [77]. Furthermore, compared to microscopy or PCR, the diagnostic cost of RDTs is relatively low, with a low cost of RDT strips and the training fees for laboratory staff. A few studies have been undertaken to evaluate the economic value of RDTs and they demonstrated that in comparison with microscopy, RDTs are more cost-effective if the whole treatment course have been taken into account [7880]. Therefore, as most of the malaria-endemic areas have limited resources, RDTs is of high value to be used there. For instance, in a large proportion of African lower-level health facilities, technical expertise and microscopy were not available for children [81]. Likewise, almost half of the suspected malaria patients seek care in the private sector in Africa [82], which could be even less equipped.

Considering the endemicity of malaria, RDTs performed in high transmission areas had higher sensitivity but lower specificity than those conducted in low-to-moderate areas. This may be because low-density infection represents a significant proportion of malaria infections among children in low-transmission settings [83,84], leading to a higher false-negative rate. Furthermore, for HRP2 based RDTs, the remaining HRP2 antigen will last for several weeks in peripheral blood after a successful treatment, leading to false-positive results $[27,57]$. This is more common in high transmission areas since the children there may be infected with P. falciparum several times across their lives $[28,60]$.

Though we did not impose any restriction on the country or region, only four studies conducted in Asia were included, and the rest of them were all performed in Africa. However, each endemic area has its own epidemiological characteristics, and the evidence of Africa cannot verify the applicability of RDTs in other 
areas. For instance, in the WHO South-East Asia Region, where the incidence rate was 7.0 per 1000 population at risk in 2017, both P. falciparum and P. vivax were dominant parasites [3,85]. P. knowlesi infection was also widely distributed there [86]. Meanwhile, most countries are confronted with the problem of limited resource. For example, India carries a high proportion of disease burden, however, microscopies were not accessible for suspected children in poor, remote villages [36,44]. Another endemic area is the WHO Americas Region, where the incidence rate was 7.3 per 1000 population at risk in 2017 [3]. Evidence demonstrated that a large proportion of $P$. falciparum lacked pfhrp 2 or pfhrp 3 or both genes there [87], which may lead to invalidity of HRP2 based RDTs. Therefore, corresponding research conducted in these areas is urgently needed.

There are two limitations to be considered in this study. First, since the parasite density of patients is a critical factor for the sensitivity of RDTs, we intended to perform a subgroup analysis. However, almost half of the included studies did not report the geometric mean parasite densities of patients, so linear regression could not be performed. Furthermore, it seemed that there was no widely-recognized standard for the classification of Plasmodium parasite density, and most of the studies classified it differently. Also, because none of the studies provided individual-level data, we could not classify the parasite density by ourselves. As a result, we could not add this factor into meta-regression and subgroup analyses, which might introduce bias. Second, our findings may be more transferable to Africa as most of the included studies were conducted there.

\section{CONCLUSIONS}

This systematic review shows the high value of RDTs in malaria diagnosis among children. Considering current prevalence of malaria, RDTs should be a suitable diagnostic test for children, especially in resource-limited areas.

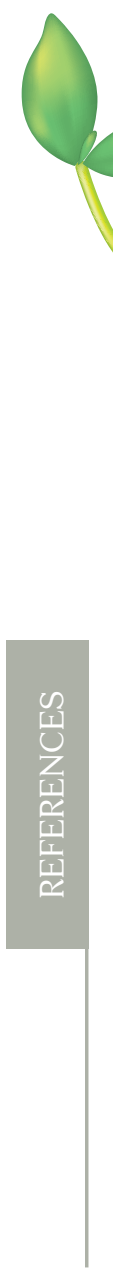

Funding: This work was funded by The Jiangsu Provincial Department of Science and Technology (No. BM2018020) and The Jiangsu Provincial Project of Invigorating Health Care through Science, Technology and Education.

Authorship contributions: JH, JC conceived and planned the study. WZ performed the data analysis and wrote the initial draft of the manuscript. WS and YD searched the literature. WZ, YD, and JL applied inclusion and exclusion criteria, extracted data, and appraised study quality. YC, MY, and GZ commented on this draft. JH, $\mathrm{XL}$, and JC critically revised the draft.

Competing interests: The authors completed the ICMJE Unified Competing Interest form (available upon request from the corresponding author), and declare no conflicts of interest.

Additional material

Online Supplementary Document

1 World Health Organization. Global Technical Strategy for Malaria 2016-2030. Geneva: World Health Organization; 2015.

2 White NJ, Pukrittayakamee S, Hien TT, Faiz MA, Mokuolu OA, Dondorp AM. Malaria. Lancet. 2014;383:723-35. Medline:23953767 doi:10.1016/S0140-6736(13)60024-0

3 World Health Organization. World malaria report 2018. Geneva: World Health Organization; 2018.

4 Yaya S, Uthman OA, Amouzou A, Bishwajit G. Mass media exposure and its impact on malaria prevention behaviour among adult women in sub-Saharan Africa: results from malaria indicator surveys. Glob Health Res Policy. 2018;3:20. Medline:29998191 doi:10.1186/s41256-018-0075-x

5 World Health Organization. Guidelines for the treatment of malaria-Third edition. Geneva: World Health Organization; 2015.

6 Nkrumah B, Acquah SEK, Ibrahim L, May J, Brattig N, Tannich E, et al. Comparative evaluation of two rapid field tests for malaria diagnosis: Partec Rapid Malaria Test ${ }^{\circledR}$ and Binax Now ${ }^{\circledR}$ Malaria Rapid Diagnostic Test. BMC Infect Dis. 2011;11:143. Medline:21605401 doi:10.1186/1471-2334-11-143

7 Cruciani M, Nardi S, Malena M, Bosco O, Serpelloni G, Mengoli C. Systematic review of the accuracy of the Parasight ${ }^{\mathrm{TM}}-\mathrm{F}$ test in the diagnosis of Plasmodium falciparum malaria. Med Sci Monit. 2004;10:MT81-8. Medline:15232515

8 Aiyenigba B, Ojo A, Aisiri A, Uzim J, Adeusi O, Mwenesi H. Immediate assessment of performance of medical laboratory scientists following a 10-day malaria microscopy training programme in Nigeria. Glob Health Res Policy. 2017;2:32. Medline:29202100 doi:10.1186/s41256-017-0051-x 
9 Abba K, Deeks JJ, Olliaro PL, Naing CM, Jackson SM, Takwoingi Y, et al. Rapid diagnostic tests for diagnosing uncomplicated P. falciparum malaria in endemic countries. Cochrane Database Syst Rev. 2011;CD008122. Medline:21735422 doi:10.1002/14651858.CD008122.pub2

10 Yerlikaya S, Campillo A, Gonzalez IJ. A Systematic Review: Performance of Rapid Diagnostic Tests for the Detection of Plasmodium knowlesi, Plasmodium malariae, and Plasmodium ovale Monoinfections in Human Blood. J Infect Dis. 2018;218:265-76. Medline:29554284 doi:10.1093/infdis/jiy150

11 Bell D, Wongsrichanalai C, Barnwell JW. Ensuring quality and access for malaria diagnosis: how can it be achieved? Nat Rev Microbiol. 2006;4:682-95. Medline:16912713 doi:10.1038/nrmicrol474

12 Abba K, Kirkham AJ, Olliaro PL, Deeks JJ, Donegan S, Garner P, et al. Rapid diagnostic tests for diagnosing uncomplicated non-falciparum or Plasmodium vivax malaria in endemic countries. Cochrane Database Syst Rev. 2014;CD011431. Medline:25519857 doi:10.1002/14651858.CD011431

13 World Health Organization. Policy brief on malaria diagnostics in low-transmission settings. Geneva: World Health Organization; 2014.

14 Bronzan RN, McMorrow ML, Kachur SP. Diagnosis of malaria: challenges for clinicians in endemic and non-endemic regions. Mol Diagn Ther. 2008;12:299-306. Medline:18803428 doi:10.1007/BF03256295

15 Li B, Sun ZQ, Li XH, Li XX, Wang H, Chen WJ, et al. Performance of pfHRP2 versus pLDH antigen rapid diagnostic tests for the detection of Plasmodium falciparum: a systematic review and meta-analysis. Arch Med Sci. 2017;13:541-9. Medline:28507567 doi:10.5114/aoms.2017.67279

16 Baird JK. Host age as a determinant of naturally acquired immunity to Plasmodium falciparum. Parasitol Today. 1995;11:105-11. Medline:15275362 doi:10.1016/0169-4758(95)80167-7

17 Rodriguez-Barraquer I, Arinaitwe E, Jagannathan P, Kamya MR, Rosenthal PJ, Rek J, et al. Quantification of anti-parasite and anti-disease immunity to malaria as a function of age and exposure. eLife. 2018;7:e35832. Medline:30044224 doi:10.7554/eLife.35832

18 Grandesso F, Nabasumba C, Nyehangane D, Page AL, Bastard M, De Smet M, et al. Performance and time to become negative after treatment of three malaria rapid diagnostic tests in low and high malaria transmission settings. Malar J. 2016;15:496. Medline:27716244 doi:10.1186/s12936-016-1529-6

19 Mtove G, Hendriksen IC, Amos B, Mrema H, Mandia V, Manjurano A, et al. Treatment guided by rapid diagnostic tests for malaria in Tanzanian children: safety and alternative bacterial diagnoses. Malar J. 2011;10:290. Medline:21978238 doi:10.1186/1475-2875-10-290

20 Keating J, Miller JM, Bennett A, Moonga HB, Eisele TP. Plasmodium falciparum parasite infection prevalence from a household survey in Zambia using microscopy and a rapid diagnostic test: Implications for monitoring and evaluation. Acta Trop. 2009;112:277-82. Medline:19682968 doi:10.1016/j.actatropica.2009.08.011

21 Rabiu OR, Kosoko AM, Falade CO, Ademowo OG. Evaluation of the Performances of Two Rapid Diagnostic Tests (Cyscope (R) mini and Paracheck-Pf (R)) in the Diagnosis of Malaria among Febrile Children in Southwest Nigeria. Med Princ Pract. 2013;22:255-9. Medline:23258268 doi:10.1159/000345642

22 Oyeyemi OT, Sode OJ, Adebayo OD, Mensah-Agyei GO. Reliability of rapid diagnostic tests in diagnosing pregnancy and infant-associated malaria in Nigeria. J Infect Public Health. 2016;9:471-7. Medline:26738923 doi:10.1016/j. jiph.2015.11.012

23 Whiting PF, Rutjes AW, Westwood ME, Mallett S, Deeks JJ, Reitsma JB, et al. QUADAS-2: a revised tool for the quality assessment of diagnostic accuracy studies. Ann Intern Med. 2011;155:529-36. Medline:22007046 doi:10.7326/00034819-155-8-201110180-00009

24 Rutter CM, Gatsonis CA. A hierarchical regression approach to meta-analysis of diagnostic test accuracy evaluations. Stat Med. 2001;20:2865-84. Medline:11568945 doi:10.1002/sim.942

25 Kattenberg JH, Ochodo EA, Boer KR, Schallig HD, Mens PF, Leeflang MM. Systematic review and meta-analysis: Rapid diagnostic tests versus placental histology, microscopy and PCR for malaria in pregnant women. Malar J. 2011;10:321. Medline:22035448 doi:10.1186/1475-2875-10-321

26 Higgins JP, Thompson SG. Quantifying heterogeneity in a meta-analysis. Stat Med. 2002;21:1539-58. Medline:12111919 doi:10.1002/sim.1186

27 Mayxay M, Pukrittayakamee S, Chotivanich K, Looareesuwan S, White NJ. Persistence of Plasmodium falciparum HRP2 in successfully treated acute falciparum malaria. Trans R Soc Trop Med Hyg. 2001;95:179-82. Medline:11355555 doi:10.1016/S0035-9203(01)90156-7

28 Gerstl S, Dunkley S, Mukhtar A, De Smet M, Baker S, Maikere J. Assessment of two malaria rapid diagnostic tests in children under five years of age, with follow-up of false-positive pLDH test results, in a hyperendemic falciparum malaria area, Sierra Leone. Malar J. 2010;9:28. Medline:20092620 doi:10.1186/1475-2875-9-28

29 Hopkins H, Kambale W, Kamya MR, Staedke SG, Dorsey G, Rosenthal PJ. Comparison of HRP2- and pLDH-based rapid diagnostic tests for malaria with longitudinal follow-up in Kampala, Uganda. Am J Trop Med Hyg. 2007;76:1092-7. Medline:17556616 doi:10.4269/ajtmh.2007.76.1092

30 Hendriksen IC, Mtove G, Pedro AJ, Gomes E, Silamut K, Lee SJ, et al. Evaluation of a PfHRP2 and a pLDH-based rapid diagnostic test for the diagnosis of severe malaria in 2 populations of African children. Clin Infect Dis. 2011;52:1100-7. Medline:21467015 doi:10.1093/cid/cir143

31 Bouyou Akotet MK, Mawili-Mboumba DP, Madoungou B, Kombila M. Performances of Malaria P.f/Pan Rapid Test Device Acon ${ }^{\circledR}$ (Pf HRP2/pan aldolase) and Malaria Pf Rapid Test Device Acon® (Pf HRP2) for the diagnosis of malaria in adults and children living in Gabon, Central Africa. Diagn Microbiol Infect Dis. 2013;77:58-63. Medline:23791385 doi:10.1016/j.diagmicrobio.2013.05.007 
32 Quakyi IA, Adjei GO, Sullivan DJ, Laar A, Stephens JK, Owusu R, et al. Diagnostic capacity, and predictive values of rapid diagnostic tests for accurate diagnosis of Plasmodium falciparum in febrile children in Asante-Akim, Ghana. Malar J. 2018;17:468. Medline:30547795 doi:10.1186/s12936-018-2613-x

33 Houzé S, Boly MD, Le Bras J, Deloron P, Faucher JF. PfHRP2 and PfLDH antigen detection for monitoring the efficacy of artemisinin-based combination therapy (ACT) in the treatment of uncomplicated falciparum malaria. Malar J. $2009 ; 8: 211$. Medline:19735557 doi:10.1186/1475-2875-8-211

34 Mens P, Spieker N, Omar S, Heijnen M, Schallig H, et al. Is molecular biology the best alternative for diagnosis of malaria to microscopy? A comparison between microscopy, antigen detection and molecular tests in rural Kenya and urban Tanzania. Trop Med Int Health. 2007;12:238-44. Medline:17300631

35 Ratsimbasoa A, Ravony H, Vonimpaisomihanta JA, Raherinjafy R, Jahevitra M, Rapelanoro R, et al. Management of uncomplicated malaria in febrile under five-year-old children by community health workers in Madagascar: Reliability of malaria rapid diagnostic tests. Malar J. 2012;11:85. Medline:22443344 doi:10.1186/1475-2875-11-85

36 Singh N, Saxena A, Sharma VP. Usefulness of an inexpensive, Paracheck ${ }^{\circledR}$ test in detecting asymptomatic infectious reservoir of Plasmodium falciparum during dry season in an inaccessible terrain in Central India. J Infect. 2002;45:165-8. Medline:12387772 doi:10.1053/jinf.2002.1055

37 Shaikh S, Memon S, Memon H, Ahmed I. Role of rapid diagnostic tests for guiding outpatient treatment of febrile illness in Liaquat University Hospital. Pak J Med Sci. 2013;29:1167-72. Medline:24353713 doi:10.12669/pjms.295.3937

38 Owusu EDA, Djonor SK, Brown CA, Grobusch MP, Mens PF. Plasmodium falciparum diagnostic tools in HIV-positive under-5-year-olds in two ART clinics in Ghana: are there missed infections? Malar J. 2018;17:92. Medline:29471833 doi:10.1186/s12936-018-2231-7

39 Kashosi TM, Mutuga JM, Byadunia DS, Mutendela JK, Mulenda B, Mubagwa K. Performance of SD Bioline Malaria Ag Pf/Pan rapid test in the diagnosis of malaria in South-Kivu, DR Congo. Pan Afr Med J. 2017;27:216. Medline:28979618 doi:10.11604/pamj.2017.27.216.11430

40 Ayeh-Kumi PF, Akalifa BG, Obeng-Nkrumah N, Asmah RH, Dayie NTKD. Performance of rapid DiaMed OptiMal-IT® malaria test in an endemic Ghanaian setting. J Parasit Dis. 2011;35:129-33. Medline:23024493 doi:10.1007/s12639011-0045-4

41 Kiemde F, Bonko MDA, Tahita MC, Lompo P, Rouamba T, Tinto H, et al. Accuracy of a Plasmodium falciparum specific histidine-rich protein 2 rapid diagnostic test in the context of the presence of non-malaria fevers, prior anti-malarial use and seasonal malaria transmission. Malar J. 2017;16:294. Medline:28728558 doi:10.1186/s12936-017-1941-6

42 Baiden F, Webster J, Tivura M, Delimini R, Berko Y, Amenga-Etego S, et al. Accuracy of Rapid Tests for Malaria and Treatment Outcomes for Malaria and Non-Malaria Cases among Under-Five Children in Rural Ghana. PLoS One. 2012;7:e34073. Medline:22514617 doi:10.1371/journal.pone.0034073

43 Premji Z, Minjas JN, Shiff CJ. Laboratory diagnosis of malaria by village health-workers using the rapid manual parasight (TM)-F test. Trans R Soc Trop Med Hyg. 1994;88:418. Medline:7570824 doi:10.1016/0035-9203(94)90409-X

44 Singh N, Shukla M. An assessment of the usefulness of a rapid immuno-chromatographic test, "Determine ${ }^{\mathrm{TM}}$ malaria pf" in evaluation of intervention measures in forest villages of central India. BMC Infect Dis. 2001;1:10. Medline:11532200 doi:10.1186/1471-2334-1-10

45 Adesanmi TA, Okafor HU, Okoro AB, Mafe AG. Diagnosis of malaria parasitemia in children using a rapid diagnostic test. Niger J Clin Pract. 2011;14:195-200. Medline:21860139 doi:10.4103/1119-3077.84015

46 Bojang KA. The diagnosis of Plasmodium falciparum infection in Gambian children, by field staff using the rapid, manual, ParaSight-F test. Ann Trop Med Parasitol. 1999;93:685-7. Medline:10715695

47 Kamugisha ML, Msangeni H, Beale E, Malecela EK, Akida J, Ishengoma DR, et al. Paracheck Pf compared with microscopy for diagnosis of Plasmodium falciparum malaria among children in Tanga City, north-eastern Tanzania. Tanzan J Health Res. 2008;10:14-9. Medline:18680960 doi:10.4314/thrb.v10il.14336

48 Valéa I, Tinto H, Nikiema M, Yamuah L, Rouamba N, Drabo M, et al. Performance of OptiMAL-IT® compared to microscopy, for malaria detection in Burkina Faso. Trop Med Int Health. 2009;14:338-40. Medline:19187517 doi:10.1111/ j.1365-3156.2009.02228.x

49 Hawkes M, Conroy AL, Opoka RO, Namasopo S, Liles WC, John CC, et al. Use of a three-band HRP2/pLDH combination rapid diagnostic test increases diagnostic specificity for falciparum malaria in Ugandan children. Malar J. 2014;13:43. Medline:24484540 doi:10.1186/1475-2875-13-43

50 Mahende C, Ngasala B, Lusingu J, Yong TS, Lushino P, Lemnge M, et al. Performance of rapid diagnostic test, blood-film microscopy and PCR for the diagnosis of malaria infection among febrile children from Korogwe District, Tanzania. Malar J. 2016;15:391. Medline:27459856 doi:10.1186/s12936-016-1450-z

51 Ilombe G, Maketa V, Mavoko HM, da Luz RI, Lutumba P, Van Geertruyden JP. Performance of HRP2-based rapid test in children attending the health centre compared to asymptomatic children in the community. Malar J. 2014;13:308. Medline:25108305 doi:10.1186/1475-2875-13-308

52 Ajumobi O, Sabitu K, Nguku P, Kwaga J, Ntadom G, Gitta S, et al. Performance of an HRP-2 Rapid Diagnostic Test in Nigerian Children Less Than 5 Years of Age. Am J Trop Med Hyg. 2015;92:828-33. Medline:25711608 doi:10.4269/ ajtmh.13-0558

53 Sotimehin SA, Runsewe-Abiodun TI, Oladapo OT, Njokanma OF, Olanrewaju DM. Performance of a rapid antigen test for the diagnosis of congenital malaria. Ann Trop Paediatr. 2007;27:297-301. Medline:18053347 doi:10.1179/146532807X245698 
54 Tarimo DS, Jani B, Killewo JZ. Management of fever among under-fives and utility of malaria rapid diagnostic test under reduced malaria burden in Rufiji District, Southeastern Tanzania. Asian Pac J Trop Dis. 2015;5:862-8. doi:10.1016/ S2222-1808(15)60946-X

55 Wanji S, Kimbi HK, Eyong JE, Tendongfor N, Ndamukong JL. Performance and usefulness of the Hexagon rapid diagnostic test in children with asymptomatic malaria living in the Mount Cameroon region. Malar J. 2008;7:89. Medline: 18498626 doi:10.1186/1475-2875-7-89

56 Tiono AB, Diarra A, Sanon S, Nebie I, Konate AT, Pagnoni F, et al. Low specificity of a malaria rapid diagnostic test during an integrated community case management trial. Infect Dis Ther. 2013;2:27-36. Medline:25135821 doi:10.1007/ s40121-013-0006-6

57 Swarthout TD, Counihan H, Senga RK, van den Broek I. Paracheck-Pf accuracy and recently treated Plasmodium falciparum infections: is there a risk of over-diagnosis? Malar J. 2007;6:58. Medline:17506881 doi:10.1186/1475-2875-6-58

58 Samadoulougou S, Kirakoya-Samadoulougou F, Sarrassat S, Tinto H, Bakiono F, Nebie I, et al. Paracheck (R) rapid diagnostic test for detecting malaria infection in under five children: a population-based survey in Burkina Faso. Malar J. 2014;13:101. Medline:24636636 doi:10.1186/1475-2875-13-101

59 Venkatesh V, Patibandla PK, Agarwal GG, Awasthi S, Ahuja RC, Nag VL, et al. Performance characteristics of a rapid diagnostic test for malaria, when used to confirm cerebral malaria in children and young adults. Ann Trop Med Parasitol. 2007;101:85-7. Medline:17244413 doi:10.1179/136485907X154647

60 Aydin-Schmidt B, Mubi M, Morris U, Petzold M, Ngasala BE, Premji Z, et al. Usefulness of Plasmodium falciparum-specific rapid diagnostic tests for assessment of parasite clearance and detection of recurrent infections after artemisinin-based combination therapy. Malar J. 2013;12:349. Medline:24079306 doi:10.1186/1475-2875-12-349

61 Adebisi NA, Dada-Adegbola HO, Dairo MD, Ajayi IO, Ajumobi OO. Performance of malaria rapid diagnostic test in febrile under-five children at Oni Memorial Children's Hospital in Ibadan, Nigeria, 2016. Pan Afr Med J. 2018;30:242. Medline:30574261

62 Al-Shehri H, Power BJ, Archer J, Cousins A, Atuhaire A, Adriko M, et al. Non-invasive surveillance of Plasmodium infection by real-time PCR analysis of ethanol preserved faeces from Ugandan school children with intestinal schistosomiasis. Malar J. 2019;18:109. Medline:30935388 doi:10.1186/s12936-019-2748-4

63 Bloch EM, Kasubi M, Levin A, Mrango Z, Weaver J, Munoz B, et al. Babesia microti and malaria infection in Africa: A pilot serosurvey in kilosa district, Tanzania. Am J Trop Med Hyg. 2018;99:51-6. Medline:29637884 doi:10.4269/ajtmh.18-0012

64 Dada-Adegbola HO, Brown BJ, Labaeka AA. Prevalence of malaria and performance of a rapid diagnostic test for malaria in febrile children with sickle cell disease. Pediatric Hematology Oncology Journal. 2018;3:42-5. doi:10.1016/j. phoj.2018.06.003

65 Nkefou CN, Hell VN, Georges NT, Ngoufack MN, Nkenfou CN, Kamgaing N, et al. Usage of a rapid diagnostic test for malaria in children. Afr J Infect Dis. 2018;13:24-31. Medline:30596193

66 Hofmann NE, Moniz CA, Holzschuh A, Keitel K, Boillat-Blanco N, Kagoro F, et al. Diagnostic Performance of Conventional and Ultrasensitive Rapid Diagnostic Tests for Malaria in Febrile Outpatients in Tanzania. J Infect Dis. 2019;219:14908. Medline:30476111 doi:10.1093/infdis/jiy676

67 Iwuafor AA, Ita OI, Ogban GI, Udoh UA, Amajor CA. Evaluation of Diagnostic Accuracy of Rapid Diagnostic Test for Malaria Diagnosis among Febrile Children in Calabar, Nigeria. Niger Med J. 2018;59:64-9. Medline:31423044 doi:10.4103/ nmj.NMJ_165_18

68 Kiemde F, Dit Achille Bonko M, Tahita MC, Mens PF, Tinto H, Schallig HDFH, et al. Algorithms for sequential interpretation of a malaria rapid diagnostic test detecting two different targets of Plasmodium species to improve diagnostic accuracy in a rural setting (Nanoro, Burkina Faso). PLoS One. 2019;14:e0211801. Medline:30759130 doi:10.1371/journal.pone.0211801

69 Kiemde F, Tahita MC, Bonko MDA, Mens PF, Tinto H, Van Hensbroek MB, et al. Implementation of a malaria rapid diagnostic test in a rural setting of Nanoro, Burkina Faso: From expectation to reality. Malar J. 2018;17:316. Medline:30165849 doi:10.1186/s12936-018-2468-1

70 Kitutu FE, Wamani H, Selling KE, Katabazi FA, Kuteesa RB, Peterson S, et al. Can malaria rapid diagnostic tests by drug sellers under field conditions classify children 5 years old or less with or without Plasmodium falciparum malaria? Comparison with nested PCR analysis. Malar J. 2018;17:365. Medline:30326926 doi:10.1186/s12936-018-2508-x

71 Peprah S, Dhudha H, Ally H, Masalu N, Kawira E, Chao CN, et al. A population-based study of the prevalence and risk factors of low-grade Plasmodium falciparum malaria infection in children aged 0-15 years old in northern Tanzania. Trop Med Int Health. 2019;24:571-85. Medline:30843638 doi:10.1111/tmi.13225

72 Teh RN, Sumbele IUN, Asoba Nkeudem G, Meduke DN, Ojong ST, Kimbi HK. Concurrence of CareStartTM Malaria HRP2 RDT with microscopy in population screening for Plasmodium falciparum infection in the Mount Cameroon area: Predictors for RDT positivity. Trop Med Health. 2019;47:17. Medline:30867636 doi:10.1186/s41182-019-0145-x

73 Mason DP, Kawamoto F, Lin K, Laoboonchai A, Wongsrichanalai C. A comparison of two rapid field immunochromatographic tests to expert microscopy in the diagnosis of malaria. Acta Trop. 2002;82:51-9. Medline:11904103 doi:10.1016/ S0001-706X(02)00031-1

74 Playford EG, Walker J. Evaluation of the ICT malaria P.f/P.v and the OptiMal rapid diagnostic tests for malaria in febrile returned travellers. J Clin Microbiol. 2002;40:4166-71. Medline:12409392 doi:10.1128/JCM.40.11.4166-4171.2002

75 Moher D, Liberati A, Tetzlaff J, Altman DG. Preferred reporting items for systematic reviews and meta-analyses: the PRISMA statement. PLoS Med. 2009;6:e1000097. Medline:19621072 doi:10.1371/journal.pmed.1000097 
76 Chan JA, Stanisic DI, Duffy MF, Robinson LJ, Lin E, Kazura JW, et al. Patterns of protective associations differ for antibodies to P. falciparum-infected erythrocytes and merozoites in immunity against malaria in children. Eur J Immunol. 2017;47:2124-36. Medline:28833064 doi:10.1002/eji.201747032

77 von Seidlein L, Olaosebikan R, Hendriksen IC, Lee SJ, Adedoyin OT, Agbenyega T, et al. Predicting the clinical outcome of severe falciparum malaria in african children: findings from a large randomized trial. Clin Infect Dis. 2012;54:108090. Medline:22412067 doi:10.1093/cid/cis034

78 Batwala V, Magnussen P, Hansen KS, Nuwaha F. Cost-effectiveness of malaria microscopy and rapid diagnostic tests versus presumptive diagnosis: implications for malaria control in Uganda. Malar J. 2011;10:372. Medline:22182735 doi:10.1186/1475-2875-10-372

79 Uzochukwu BS, Obikeze EN, Onwujekwe OE, Onoka CA, Griffiths UK. Cost-effectiveness analysis of rapid diagnostic test, microscopy and syndromic approach in the diagnosis of malaria in Nigeria: implications for scaling-up deployment of ACT. Malar J. 2009;8:265. Medline:19930666 doi:10.1186/1475-2875-8-265

80 Ling XX, Jin JJ, Zhu GD, Wang WM, Cao YY, Yang MM, et al. Cost-effectiveness analysis of malaria rapid diagnostic tests: a systematic review. Infect Dis Poverty. 2019;8:104. Medline:31888731 doi:10.1186/s40249-019-0615-8

81 Boyce MR, O'Meara WP. Use of malaria RDTs in various health contexts across sub-Saharan Africa: a systematic review. BMC Public Health. 2017;17:470. Medline:28521798 doi:10.1186/s12889-017-4398-1

82 Moon S, Casas CP, Kindermans JM, de Smet M, von Schoen-Angerer T. Focusing on Quality Patient Care in the New Global Subsidy for Malaria Medicines. PLoS Med. 2009;6:e1000106. Medline:19621068 doi:10.1371/journal.pmed.1000106

83 Okell LC, Ghani AC, Lyons E, Drakeley CJ. Submicroscopic infection in Plasmodium falciparum-endemic populations: a systematic review and meta-analysis. J Infect Dis. 2009;200:1509-17. Medline:19848588 doi:10.1086/644781

84 Okell LC, Bousema T, Griffin JT, Ouedraogo AL, Ghani AC, Drakeley CJ. Factors determining the occurrence of submicroscopic malaria infections and their relevance for control. Nat Commun. 2012;3:1237. Medline:23212366 doi:10.1038/ ncomms 2241

85 Bharati K, Ganguly NK. Tackling the malaria problem in the South-East Asia Region: need for a change in policy? Indian J Med Res. 2013;137:36-47. Medline:23481050

86 Karunajeewa H, Berman J. Is the epidemiology of Plasmodium knowlesi changing and what does this mean for malaria control in South East Asia? Clin Infect Dis. 2020;70:368-9. Medline:30888013

87 Gamboa D, Ho MF, Bendezu J, Torres K, Chiodini PL, Barnwell JW, et al. A large proportion of P. falciparum isolates in the Amazon region of Peru lack pfhrp2 and pfhrp3: implications for malaria rapid diagnostic tests. PLoS One. 2010;5:e8091. Medline:20111602 doi:10.1371/journal.pone.0008091 